\title{
Diagnostic utility of thyroid transcription factors Pax8 and TTF-2 (FoxE1) in thyroid epithelial neoplasms
}

\author{
Daisuke Nonaka ${ }^{1}$, Yunjia Tang ${ }^{1}$, Luis Chiriboga ${ }^{1}$, Michael Rivera $^{2}$ and Ronald Ghossein ${ }^{2}$ \\ ${ }^{1}$ Department of Pathology, New York University School of Medicine, New York, NY, USA and ${ }^{2}$ Department \\ of Pathology, Memorial Sloan-Kettering Cancer Center, New York, NY, USA
}

\begin{abstract}
Thyroid-specific transcription factors, Pax8, TTF-1, and TTF-2, are crucial for thyroid organogenesis and differentiation. Compared with TTF-1, the other two markers have scarcely been investigated in surgical pathology. The goal of this study is to evaluate the expressions of these markers in thyroid tumors of the full spectrum of differentiation, with special emphasis on anaplastic carcinomas. A total of 94 cases of thyroid neoplasms were studied: 17 papillary carcinomas, 18 follicular adenomas, 16 follicular carcinomas, 7 poorly differentiated carcinomas, 28 anaplastic carcinomas, and 8 medullary carcinomas. Immunostains for these three markers were performed. The antibodies to Pax8 and TTF-2 were also applied on 147 lung carcinomas as well as a variety of normal tissues and malignant tumors. All three markers were seen in papillary carcinomas, follicular adenomas and carcinomas, and poorly differentiated carcinomas in a diffuse manner, whereas their expressions in medullary carcinomas were variable. Pax8 was expressed in $79 \%$ of anaplastic carcinomas to a variable extent, whereas TTF-1 and TTF-2 were seen only in 18 and $7 \%$ of anaplastic carcinomas, respectively. TTF-2 was negative in all other neoplastic and non-neoplastic tissues including those of the lung. Pax8 was expressed in renal tubules, fallopian tubes, ovarian inclusion cysts, and lymphoid follicles as well as renal carcinoma, nephroblastoma, seminoma, and ovarian carcinoma, but not in normal tissue and carcinomas of the lung. Pax8 is a useful marker for the diagnosis of anaplastic carcinomas, particularly when the differential diagnosis includes pulmonary carcinoma. In differentiated thyroid neoplasms, no significant difference in expression was seen in all the three transcription factors.
\end{abstract}

Modern Pathology (2008) 21, 192-200; doi:10.1038/modpathol.3801002; published online 14 December 2007

Keywords: Pax8; TTF-2; FoxE1; TTF-1; thyroid neoplasms; anaplastic thyroid carcinoma

TTF-1 is one of the most commonly used markers in diagnostic pathology. It has shown a very high sensitivity and specificity in the diagnosis of tumors of pulmonary and thyroid lineage. In the vast majority of thyroid tumors, a diagnosis can be confidently rendered based on routine histologic examination. Immunohistochemistry study is, however, needed in some instances. The latter situations include anaplastic thyroid carcinoma and its discrimination from metastatic poorly differentiated tumors to the thyroid gland and neck, especially lung carcinomas. TTF- 1 is one of the three most important transcription factors for thyroid gland organogenesis. In contrast to TTF-1, the other two

Correspondence: Dr D Nonaka, MD, Department of Pathology, New York University School of Medicine, TCH-461, 560 First Avenue, New York, NY 10016, USA.

E-mail: daisuke.nonaka@med.nyu.edu

Received 04 September 2007; revised 04 October 2007; accepted 08 October 2007; published online 14 December 2007 transcription factors, Pax8 and TTF-2 (FoxE1), have been rarely studied for diagnostic purposes. ${ }^{1} \mathrm{We}$, hereby, describe expressions of the three thyroidrelated transcription factors on the full spectrum of primary thyroid epithelial neoplasms, and discuss the utility of the markers from a diagnostic perspective, with special emphasis on their expressions in anaplastic carcinomas.

\section{Materials and methods}

Thyroid Epithelial Neoplasms

Case selection

A total of 94 cases of primary thyroid neoplasms were retrieved from the archives of the Department of Pathology of New York University Medical Center and Memorial Sloan-Kettering Cancer Center. The cases include 17 cases of papillary carcinoma, 18 cases of follicular adenoma, 16 cases of follicular carcinoma, 7 cases of poorly differentiated (insular) 
carcinoma, 28 cases of anaplastic carcinoma, 8 cases of medullary carcinoma, and 2 cases of C-cell hyperplasia. Hematoxylin and eosin (H\&E) stained slides of all the cases were reviewed, and the histologic diagnosis was based on the most recent WHO classification of tumors of endocrine organs. ${ }^{2}$ Anaplastic carcinomas were further subdivided into morphologic variants based on the predominant pattern. ${ }^{3}$

\section{Tissue microarray construction}

Sixty-nine of the 94 cases of thyroid epithelial neoplasms were used for tissue microarray construction using formalin-fixed, paraffin-embedded tissue. Tissue microarrays were assembled using a Manual Tissue Arrayer I (Beecher Instruments, Sun Prairie, WI, USA) as described previously., ${ }^{4,5}$ A representative area of each case was identified on the conventional sections, and at least three cylinders per tissue were arrayed using a punch biopsy (needles with a diameter of $0.6 \mathrm{~mm}$ ).

\section{Whole tissue sections for immunostaining}

Thirteen out of the 69 cases including all 3 anaplastic carcinomas and 8 medullary carcinomas, in addition to the tissue microarray sections, were selected and examined using conventional whole sections. A further 25 cases of anaplastic carcinomas and 2 cases of C-cell hyperplasia were examined only on the conventional whole tissue sections.

\section{Non-Thyroid Malignant Tumors and Normal Tissues}

Tissue microarrays were also assembled as follows: (1) 147 cases of primary lung carcinoma, including 114 cases of adenocarcinoma, 29 cases of squamous cell carcinoma, and 4 cases of large cell carcinoma; (2) 95 malignant tumors from 14 different organs, including esophagus (squamous cell carcinoma), stomach (adenocarcinoma), colon (adenocarcinoma), liver (hepatocellular carcinoma), pancreas (ductal carcinoma), kidney (clear cell carcinoma, nephroblastoma), breast (invasive ductal carcinoma, invasive lobular carcinoma), ovary (serous papillary carcinoma, endometrioid carcinoma, clear cell carcinoma), prostate gland (adenocarcinoma), urinary bladder (urothelial carcinoma), skin (squamous cell carcinoma), testis (seminoma), lymph node (diffuse large B-cell lymphoma), and soft tissue (rhabdomyosarcoma); and (3) 53 cores of normal tissue from 17 organs, including esophagus, stomach, colon, prostate, lung, liver, kidney, breast, uterine cervix, ovary, fallopian tube, urinary bladder, skin, pancreas, testis, tongue, and placenta.

\section{Immunohistochemistry}

Immunohistochemical studies were performed using the following antibodies: rabbit anti-human Pax8 (polyclonal, Protein Tech Group Inc., Chicago,
IL, USA), mouse anti-human TTF-1 (clone 8G7G3/1, Neomarkers, Fremont, CA, USA), and goat antihuman TTF-2 (FoxE1) (polyclonal, Abcam Inc., Cambridge, MA, USA). TTF-2 and Pax8 staining was performed on all the above-mentioned tissues, that is all the thyroid tumors, tissue microarrays of (1), (2), and (3), whereas TTF-1 staining was only applied on all the thyroid tumors.

The sections were deparaffinized in xylene (three changes), rehydrated through graded alcohols (three changes $100 \%$ ethanol, three changes $95 \%$ ethanol) and rinsed in distilled water. Heat-induced epitope retrieval was performed in a 1200-W microwave oven at $90 \%$ power in $10 \mathrm{mM}$ citrate buffer pH 6.0. Pax8 and TTF-2 were retrieved for $10 \mathrm{~min}$ and TTF-1 was retrieved for $15 \mathrm{~min}$. Sections were allowed to cool for $30 \mathrm{~min}$ and then rinsed in distilled water. Antibody incubations and detection were carried out at $37^{\circ} \mathrm{C}$ on a NEXes instrument (Ventana Medical Systems, Tucson, Arizona) using Ventana's reagent buffer and detection kits unless otherwise noted. Endogenous peroxidase activity was blocked with hydrogen peroxide. Antibodies against TTF-1 and TTF-2 were diluted 1:50 and Pax8 was diluted 1:25. All antibodies were incubated overnight at room temperature. TTF-2 was detected using a biotinylated horse anti-goat (Vector Laboratories, Burlingame, CA, USA) diluted 1:100 and incubated for 30 min. TTF1 and Pax8 were detected with Ventana's biotinylated goat anti-mouse secondary. After secondary antibody application, streptavidin-horseradish peroxidase conjugate was applied. The complex was visualized with 3,3 diaminobenzidene and enhanced with copper sulfate. Slides were washed in distilled water, counterstained with hematoxylin, dehydrated and mounted with permanent media. Appropriate positive and negative controls were included with the study sections.

Two pathologists with special interest in lung (DN) and thyroid gland (RG, DN) scored the immunostains. The extent of nuclear staining was estimated and graded as follows: $1+, 1-25 \% ; 2+$, $25-50 \% ; 3+, 50-75 \% ; 4+$, $\geq 75 \%$.

\section{Results}

\section{Clinicopathologic Features}

Basic clinicopathologic findings are listed in Table 1. All cases of papillary carcinomas were of the conventional type except for one case of a follicular variant (Figure 1a). Eighteen cases of follicular adenoma included 10 cases of oncocytic variant (Hürthle cell adenoma), and 16 cases of follicular carcinoma (Figure 1e) included 3 cases of oncocytic variant (Hürthle cell carcinoma).

Most of the anaplastic carcinomas contained more than one morphologic pattern, and they were subdivided based on the predominant pattern. They constituted five cases of squamoid type, eight cases of squamous cell type (squamous cell carcinoma), 
Table 1 Clinical characteristics

\begin{tabular}{|c|c|c|c|c|c|c|}
\hline & $P C A$ & $F A$ & $F C A$ & $I C A$ & $A C A$ & $M C A$ \\
\hline Total number of cases & 17 & 18 & 16 & 7 & 28 & 8 \\
\hline Age (years) (median) & 18-83 (47) & $27-82(52)$ & $27-69(47.5)$ & 25-85 (63) & $32-90(67)$ & $16-75(46.5)$ \\
\hline Sex & $6 \mathrm{M}: 11 \mathrm{~F}$ & $3 \mathrm{M}: 15 \mathrm{~F}$ & $7 \mathrm{M}: 9 \mathrm{~F}$ & $3 \mathrm{M}: 4 \mathrm{~F}$ & $12 \mathrm{M}: 16 \mathrm{~F}$ & $3 \mathrm{M}: 5 \mathrm{~F}$ \\
\hline Tumor size (cm) (median) & $0.5-8(1.5)$ & $1.1-4.5(2.0)$ & $1.2-5.5(2.5)$ & $2-5.5(3.5)$ & $1.8-9.5(5.5)$ & $0.5-3(1.0)$ \\
\hline
\end{tabular}

PCA, papillary carcinoma; FA, follicular adenoma; FCA, follicular carcinoma; ICA, poorly differentiated carcinoma; ACA, anaplastic carcinoma; MCA, medullary carcinoma.
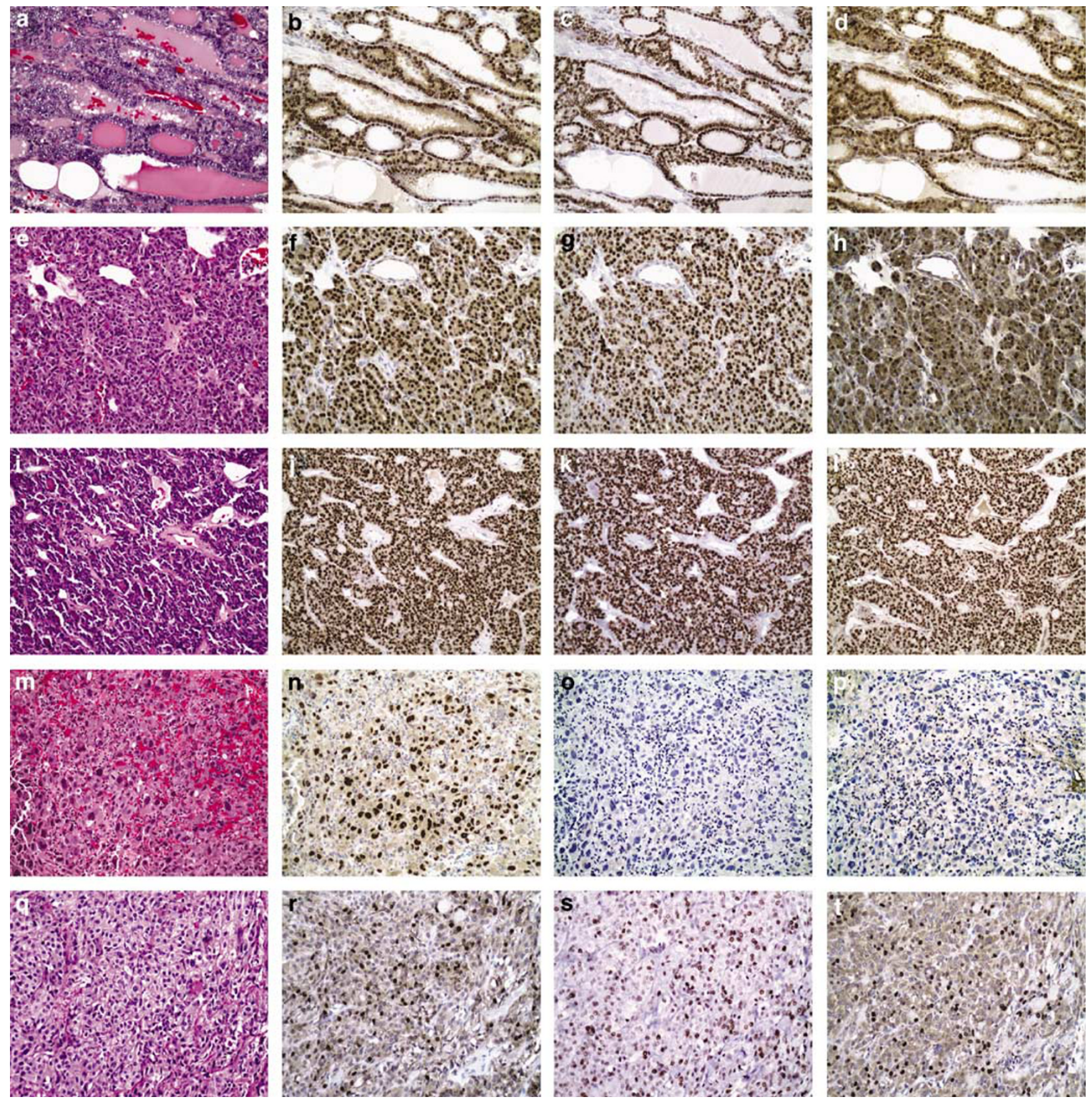

Figure 1 Papillary carcinoma: (a) H\&E stain, (b) Pax8, (c) TTF-1, (d) TTF-2. Follicular carcinoma: (e) H\&E stain, (f) Pax8, (g) TTF-1, (h) TTF-2. Poorly differentiated carcinoma: (i) H\&E stain, (j) Pax8, (k) TTF-1, (l) TTF-2. Anaplastic carcinoma: (m) H\&E stain, (n) Pax8, (o) TTF-1, (p) TTF-2. Medullary carcinoma: (q) H\&E stain, (r) Pax8, (s) TTF-1, (t) TTF-2. 
six cases of spindle cell sarcomatoid type including one case of hemangiopericytoma-like morphology, two cases of giant cell type (Figure 1m), five cases of solid epithelioid type, and two cases of rhabdoid type.

\section{Immunohistochemical Features}

The results of the immunohistochemistry study on all types of thyroid tumors are presented in Table 2A. Further analysis of morphologic subtypes of anaplastic carcinomas is listed in Table 2B. Pax8 was diffusely and strongly expressed in a nuclear pattern in all papillary carcinomas (Figure 1b), follicular adenomas, follicular carcinomas (Figure 1f), and poorly differentiated carcinomas (Figure 1j). Seventy-nine percent of anaplastic carcinomas showed a positive reaction to a variable extent and intensity (Figure 1n). The expression was focal in $75 \%$ of the medullary carcinomas (Figure 1r). Pax8 was expressed in thyroid follicular cells of normal thyroid glands in a diffuse manner, and expressed in a few C-cells in thyroid C-cell hyperplasia. In other tumors, Pax8 was expressed in nephroblastoma and ovarian serous carcinoma in a diffuse and strong manner, and clear cell renal carcinoma and seminoma in a focal reaction (Table 3). Pax8, however, was not detected in lung carcinomas, and tumors of any other organs and sites. In normal tissues, Pax8 was expressed in renal tubules, epithelial cells of the fallopian tube, and ovarian inclusion cysts as well as lymphoid follicles of lymph nodes and tonsils, but not in lung parenchyma including alveolar pneumocytes and bronchiolar epithelial cells.

Diffuse and strong TTF-1 nuclear staining was seen in all papillary carcinomas (Figure 1c), follicular adenomas, follicular carcinoma (Figure 1g), and poorly differentiated carcinomas (Figure 1k), whereas its expression in medullary carcinomas was variable (Figure 1s). TTF-1 was generally negative in anaplastic carcinomas (Figure 10), with only $18 \%$ of the cases being focally positive.

TTF-2 expression was generally diffuse and strong in all the papillary carcinomas (Figure 1d), follicular adenomas, follicular carcinomas (Figure 1h), and poorly differentiated carcinomas (Figure 1l). Seventy-five percent of the medullary carcinomas showed only focal nuclear expression (Figure 1t). A majority of anaplastic carcinomas were nonreactive to TTF-2 (Figure 1p), with only two cases $(7 \%)$ of the cases showing focal $(1+, 1-25 \%)$ nuclear staining. TTF-2 was expressed in thyroid follicular cells of normal thyroid glands in a diffuse manner, and expressed in a few $\mathrm{C}$ cells in thyroid C-cell hyperplasia. TTF-2 was negative in all other neoplastic and non-neoplastic tissues including those of the lung.

Table 2A Immunohistochemistry study results for thyroid epithelial neoplasms

\begin{tabular}{|c|c|c|c|c|c|c|c|c|c|c|c|c|c|c|c|c|c|c|}
\hline & \multicolumn{6}{|c|}{ Pax8 } & \multicolumn{6}{|c|}{$T T F-1$} & \multicolumn{6}{|c|}{$T T F-2$} \\
\hline & 0 & $1+$ & $2+$ & $3+$ & $4+$ & & 0 & $1+$ & $2+$ & $3+$ & $4+$ & & 0 & $1+$ & $2+$ & $3+$ & $4+$ & \\
\hline Papillary carcinoma & 0 & 0 & 0 & 0 & 17 & $17 / 17(100 \%)$ & 0 & 0 & 0 & 0 & 17 & $17 / 17(100 \%)$ & 0 & 0 & 0 & 5 & 12 & $17 / 17(100 \%)$ \\
\hline Follicular adenoma & 0 & 0 & 0 & 1 & 17 & $18 / 18(100 \%)$ & 0 & 0 & 2 & 0 & 16 & $18 / 18(100 \%)$ & 0 & 0 & 2 & 2 & 14 & $18 / 18(100 \%)$ \\
\hline Follicular carcinoma & 0 & 0 & 0 & 3 & 13 & $16 / 16(100 \%)$ & 0 & 0 & 0 & 1 & 15 & $16 / 16(100 \%)$ & 0 & 0 & 0 & 4 & 12 & $16 / 16(100 \%)$ \\
\hline $\begin{array}{l}\text { Poorly differentiated } \\
\text { carcinoma }\end{array}$ & 0 & 0 & 0 & 0 & 7 & $7 / 7(100 \%)$ & 0 & 0 & 0 & 1 & 6 & $7 / 7(100 \%)$ & 0 & 0 & 0 & 1 & 6 & $7 / 7(100 \%)$ \\
\hline Anaplastic carcinoma & 6 & 4 & 5 & 5 & 8 & $22 / 28(79 \%)$ & 23 & 4 & 1 & 0 & 0 & $5 / 28(18 \%)$ & 26 & 2 & 0 & 0 & 0 & $2 / 28(7 \%)$ \\
\hline Medullar carcinoma & 2 & 5 & 1 & 0 & 0 & $6 / 8(75 \%)$ & 1 & 3 & 2 & 0 & 2 & $7 / 8(88 \%)$ & 2 & 5 & 1 & 0 & 0 & $6 / 8(75 \%)$ \\
\hline
\end{tabular}

0 indicates no staining; $1+, 1-25 \%$ tumor cells reactive; $2+, 25-50 \%$ tumor cells reactive; $3+, 50-75 \%$ tumor cells reactive; $4+, \geq 75 \%$ tumor cells reactive.

Table 2B Immunohistochemistry study results for anaplastic carcinomas

\begin{tabular}{|c|c|c|c|c|c|c|c|c|c|c|c|c|c|c|c|c|c|c|}
\hline & \multicolumn{6}{|c|}{ Pax8 } & \multicolumn{6}{|c|}{$T T F-1$} & \multicolumn{6}{|c|}{$T T F-2$} \\
\hline & 0 & $1+$ & $2+$ & $3+$ & $4+$ & & 0 & $1+$ & $2+$ & $3+$ & $4+$ & & 0 & $1+$ & $2+$ & $3+$ & $4+$ & \\
\hline Squamoid & 1 & 1 & 1 & 1 & 1 & $4 / 5(80 \%)$ & 4 & 1 & 0 & 0 & 0 & $1 / 5(20 \%)$ & 0 & 0 & 0 & 0 & 0 & $0 / 5(0 \%)$ \\
\hline Squamous cell & 0 & 1 & 2 & 2 & 3 & $8 / 8(100 \%)$ & 8 & 0 & 0 & 0 & 0 & $0 / 8(0 \%)$ & 8 & 0 & 0 & 0 & 0 & $0 / 8(0 \%)$ \\
\hline Spindle & 3 & 0 & 1 & 2 & 0 & $3 / 6(50 \%)$ & 5 & 1 & 0 & 0 & 0 & $1 / 6(17 \%)$ & 5 & 1 & 0 & 0 & 0 & $1 / 6(17 \%)$ \\
\hline Giant cell & 0 & 0 & 0 & 0 & 2 & $2 / 2(100 \%)$ & 1 & 1 & 0 & 0 & 0 & $1 / 2(50 \%)$ & 1 & 1 & 0 & 0 & 0 & $1 / 2(50 \%)$ \\
\hline Epithelioid & 2 & 2 & 1 & 0 & 0 & $3 / 5(60 \%)$ & 3 & 1 & 1 & 0 & 0 & $2 / 5(40 \%)$ & 5 & 0 & 0 & 0 & 0 & $0 / 5(0 \%)$ \\
\hline Rhabdoid & 0 & 0 & 0 & 0 & 2 & 2/2 (100\%) & 2 & 0 & 0 & 0 & 0 & $0 / 2(0 \%)$ & 2 & 0 & 0 & 0 & 0 & $0 / 2(0 \%)$ \\
\hline
\end{tabular}

0 indicates no staining; $1+, 1-25 \%$ tumor cells reactive; $2+, 25-50 \%$ tumor cells reactive; $3+, 50-75 \%$ tumor cells reactive; $4+, \geq 75 \%$ tumor cells reactive. 
Table 3 Immunohistochemistry study results for non-thyroid neoplasms

\begin{tabular}{|c|c|c|c|c|c|c|c|c|c|c|c|c|}
\hline & \multicolumn{6}{|c|}{$P A X 8$} & \multicolumn{6}{|c|}{$T T F-2$} \\
\hline & 0 & $1+$ & $2+$ & $3+$ & $4+$ & & 0 & $1+$ & $2+$ & $3+$ & $4+$ & \\
\hline \multicolumn{13}{|l|}{ Lung } \\
\hline Adenocarcinoma & 114 & 0 & 0 & 0 & 0 & $0 / 114(0 \%)$ & 114 & 0 & 0 & 0 & 0 & $0 / 114(0 \%)$ \\
\hline Squamous cell carcinoma & 29 & 0 & 0 & 0 & 0 & $0 / 29(0 \%)$ & 29 & 0 & 0 & 0 & 0 & $0 / 29(0 \%)$ \\
\hline Large cell carcinoma & 4 & 0 & 0 & 0 & 0 & $0 / 4(0 \%)$ & 4 & 0 & 0 & 0 & 0 & $0 / 4(0 \%)$ \\
\hline \multicolumn{13}{|l|}{ Esophagus } \\
\hline Squamous cell carcinoma & 6 & 0 & 0 & 0 & 0 & $0 / 6(0 \%)$ & 6 & 0 & 0 & 0 & 0 & $0 / 6(0 \%)$ \\
\hline \multicolumn{13}{|l|}{ Stomach } \\
\hline Adenocarcinoma & 5 & 0 & 0 & 0 & 0 & $0 / 5(0 \%)$ & 5 & 0 & 0 & 0 & 0 & $0 / 5(0 \%)$ \\
\hline \multicolumn{13}{|l|}{ Colon } \\
\hline Adenocarcinoma & 8 & 0 & 0 & 0 & 0 & $0 / 8(0 \%)$ & 8 & 0 & 0 & 0 & 0 & $0 / 8(0 \%)$ \\
\hline \multicolumn{13}{|l|}{ Pancreas } \\
\hline Adenocarcinoma & 5 & 0 & 0 & 0 & 0 & $0 / 5(0 \%)$ & 5 & 0 & 0 & 0 & 0 & $0 / 5(0 \%)$ \\
\hline \multicolumn{13}{|l|}{ Liver } \\
\hline Hepatocellular carcinoma & 6 & 0 & 0 & 0 & 0 & $0 / 6(0 \%)$ & 6 & 0 & 0 & 0 & 0 & $0 / 6(0 \%)$ \\
\hline \multicolumn{13}{|l|}{ Kidney } \\
\hline Nephroblastoma & 0 & 0 & 0 & 2 & 0 & $2 / 2(100 \%)$ & 2 & 0 & 0 & 0 & 0 & $0 / ?(0 \%)$ \\
\hline Renal cell carcinoma & 0 & 0 & 2 & 3 & 0 & $5 / 5(100 \%)$ & 5 & 0 & 0 & 0 & 0 & $0 / 5(0 \%)$ \\
\hline \multicolumn{13}{|l|}{ Breast } \\
\hline Invasive ductal carcinoma & 10 & 0 & 0 & 0 & 0 & $0 / 10(0 \%)$ & 10 & 0 & 0 & 0 & 0 & $0 / 10(0 \%)$ \\
\hline Invasive lobular carcinoma & 10 & 0 & 0 & 0 & 0 & $0 / 10(0 \%)$ & 10 & 0 & 0 & 0 & 0 & $0 / 10(0 \%)$ \\
\hline \multicolumn{13}{|l|}{ Ovary } \\
\hline Serous papillary carcinoma & 0 & 0 & 0 & 0 & 10 & $10 / 10(100 \%)$ & 10 & 0 & 0 & 0 & 0 & $0 / 10(0 \%)$ \\
\hline Endometrioid carcinoma & 1 & 0 & 0 & 1 & 1 & $2 / 3(67 \%)$ & 3 & 0 & 0 & 0 & 0 & $0 / 3(0 \%)$ \\
\hline Clear cell carcinoma & 0 & 0 & 0 & 0 & 2 & $2 / 2(100 \%)$ & 2 & 0 & 0 & 0 & 0 & $0 / 2(0 \%)$ \\
\hline \multicolumn{13}{|l|}{ Prostate } \\
\hline Adenocarcinoma & 6 & 0 & 0 & 0 & 0 & $0 / 6(0 \%)$ & 6 & 0 & 0 & 0 & 0 & $0 / 6(0 \%)$ \\
\hline \multicolumn{13}{|l|}{ Urinary bladder } \\
\hline Urothelial carcinoma & 5 & 0 & 0 & 0 & 0 & $0 / 5(0 \%)$ & 5 & 0 & 0 & 0 & 0 & $0 / 5(0 \%)$ \\
\hline \multicolumn{13}{|l|}{ Skin } \\
\hline Squamous cell carcinoma & 4 & 0 & 0 & 0 & 0 & $0 / 4(0 \%)$ & 4 & 0 & 0 & 0 & 0 & $0 / 4(0 \%)$ \\
\hline \multicolumn{13}{|l|}{ Testis } \\
\hline Seminoma & 1 & 1 & 1 & 0 & 0 & $2 / 3(67 \%)$ & 3 & 0 & 0 & 0 & 0 & $0 / 3(0 \%)$ \\
\hline \multicolumn{13}{|l|}{ Lymph node } \\
\hline Diffuse large B-cell lymphoma & 3 & 0 & 0 & 0 & 0 & $0 / 3(0 \%)$ & 3 & 0 & 0 & 0 & 0 & $0 / 3(0 \%)$ \\
\hline \multicolumn{13}{|l|}{ Soft tissue } \\
\hline Rhabdomyosarcoma & 2 & 0 & 0 & 0 & 0 & $0 / 2(0 \%)$ & 2 & 0 & 0 & 0 & 0 & $0 / 2(0 \%)$ \\
\hline
\end{tabular}

0 indicates no staining; $1+, 1-25 \%$ tumor cells reactive; $2+, 25-50 \%$ tumor cells reactive; $3+, 50-75 \%$ tumor cells reactive; $4+$, $\geq 75 \%$ tumor cells reactive.

\section{Discussion}

Primary thyroid and lung carcinomas are common neoplasms, accounting for approximately 3 and $12 \%$ of all malignancies, respectively. ${ }^{6}$ Thyroid carcinoma is the most common type of endocrine malignancy, accounting for $90 \%$ of all endocrine malignant tumors. It is, therefore, not uncommon that the same patients suffer from both neoplasms, synchronously or metachronously. The lung is the most common distant metastatic site for thyroid carcinomas (49\%), followed by bone $(25 \%)$ and brain $(10 \%) .{ }^{7}$ The latter two organs, bone and brain, are also common metastatic destinations for lung carcinomas, and metastases to them are found in 30 and $45 \%$ of patients with metastasis to distant organs, respectively. ${ }^{8}$ Although rare, lung carcinoma can metastasize to the thyroid gland, with the reported incidence of clinically detected cases ranging from 0.05 to $3.1 \% .^{9-11}$ Metastatic thyroid 
carcinoma in the lung may grow slowly, remain solely for an extended period of time, and may, therefore, simulate a primary pulmonary neoplasm. ${ }^{12}$ Some lung and thyroid carcinomas may have similar morphologic features. For example, features typical of conventional papillary carcinoma such as papillary architecture, psammoma bodies, and nuclear pseudoinclusions and grooves can be seen in non-mucinous bronchioloalveolar and papillary types of lung adenocarcinoma. Anaplastic spindle and giant cells are found in both pleomorphic carcinoma of the lung and anaplastic thyroid carcinoma. ${ }^{8,13}$ In addition, both thyroid and lung carcinomas generally share TTF-1 immunoreactivity. Indeed, TTF-1 is positive in $75 \%$ of lung adenocarcinomas, ${ }^{14}$ and almost all cases of well-differentiated thyroid neoplasms of follicular origin. ${ }^{15}$ Thorough routine microscopic examination, along with adequate clinical and radiographic information, generally would allow a definitive diagnosis in such a setting. Immunohistochemistry study can further solidify the diagnosis. Welldifferentiated thyroid carcinomas of follicular origin always express thyroglobulin, whereas well-differentiated lung adenocarcinomas express surfactant proteins such as surfactant apoprotein A in approximately $50 \%$ of cases. ${ }^{14,16}$ A minority of differentiated tumors and a majority of poorly and undifferentiated carcinomas may cause a diagnostic problem due to the lack of differentiation markers. In fact, thyroglobulin may be identified in less than half of poorly differentiated thyroid carcinomas. ${ }^{17}$ Furthermore, thyroglobulin and surfactant protein are completely negative in all anaplastic thyroid carcinomas and pulmonary pleomorphic carcinomas. ${ }^{18-20}$ Even the transcription factor TTF-1 is expressed only in $5.7 \%{ }^{21}$ of anaplastic thyroid carcinomas, and $55 \%$ of lung pleomorphic carcinomas. ${ }^{20}$

The diagnosis of anaplastic carcinomas, which is the least differentiated thyroid epithelial neoplasm, is conventionally based, similarly to undifferentiated carcinomas of other organs such as upper aerodigestive tract and uterus, on: (1) a presence of differentiated thyroid carcinoma componentusually papillary carcinomas but also follicular carcinomas and poorly differentiated carcinomaswhich can be found in $50-89 \%$ of well-sampled cases; (2) involvement of the bulk of the tumor in the thyroid gland; (3) exclusion of undifferentiated tumor by metastasis or direct invasion from a neighboring organ, such as larynx. Immunohistochemistry has not been reliable in identifying the origin of the organ due to a lack of thyroglobulin and TTF-1 expression as mentioned earlier.

Transcription factors are proteins that control the first step of gene expression, and their role is to orchestrate the complex pathways of cellular growth and differentiation. ${ }^{22}$ Some of these molecules are tissue/organ-specific, and they are frequently expressed at an early stage of embryogenesis where they regulate specific differentiation pathways.
These features make them particularly helpful for determining cell lineage of tumors. Among transcription factors, the most commonly used and certainly the most useful marker in diagnostic pathology is TTF-1. In thyroid organogenesis, in addition to $T t f-1$, two more transcription factors are crucially involved: Pax8 and Ttf-2 (Foxe1).

The development of the thyroid gland and its normal migration in the embryonic stage, and furthermore, the maintenance of the differentiated state throughout its life is dependent on the interplay between transcription factors, particularly Pax8, Ttf-1, and $T t f-2 .{ }^{23}$ These transcription factors act to maintain the thyroid-differentiated phenotype $^{24,25}$ Among the three transcription factors, the Pax8 gene is the first to be expressed in the median thyroid anlage and laterally in the fourth pharyngeal arch, followed by the $T t f-1$ gene, and then $T t f-2{ }^{23}$ The importance of these three transcription factors is evidenced by congenital thyroid agenesis, which results from mutations in any of the transcription factors. ${ }^{26-32}$

We found consistent nuclear expressions of Pax8, TTF-1, and TTF-2 in well-differentiated neoplasms of follicular cell origin, that is, papillary carcinomas, follicular adenomas, follicular carcinomas, and poorly differentiated carcinomas. Seventy-nine percent of anaplastic carcinomas variably showed Pax8 reaction, whereas TTF-1 and TTF2 were expressed in only 18 and $7 \%$ of anaplastic carcinomas, respectively. In light of the chronological emergence of these transcription factors in thyroid organogenesis, that is, Pax8 at first, followed by Ttf-1 and $T t f-2$, the latter finding is no surprise, since it is generally observed that more mature differentiation markers become lost at an early stage of tumor progression, and $\operatorname{Pax} 8$ is the earliest transcription factor in thyroid embryogenesis, that is, the marker found at the most immature stage of the thyroid anlage ${ }^{33}$ In fact, loss of thyroid-specific proteins and differentiation has been described as a common process in thyroid carcinogenesis. ${ }^{1,34,35}$

Medullary carcinomas expressed all three markers to a variable extent in most cases in our study. TTF-1 generally showed more extensive staining than Pax8 and TTF-2. This finding is interesting, since $\mathrm{C}$ cell, which medullary carcinoma originates from, is of ultimobranchial body derivation. Ttf-1 is expressed in the ultimobranchial body, and it was proposed that $T t f-1$ may regulate the calcitonin gene in the maintenance of calcium homeostasis in C cells. ${ }^{36,37}$ Pax8 expression was also demonstrated in the ultimobranchial body, but its role in $\mathrm{C}$ cells remains largely unclear. ${ }^{23}$ A relation of $T t f-2$ to the ultimobranchial body has not been reported to our knowledge. Pax8 and TTF-2 were expressed in C cells of C-cell hyperplasia. Given that all of the three transcription factors are expressed in medullary carcinomas and C-cell hyperplasia, it can be speculated that they may play some role not only in follicular cells but also in C-cell development. 
Previous studies of Pax8 expression in thyroid neoplasms showed discrepant results. By immunohistochemistry, this molecule was shown to be expressed in $33-100 \%$ of follicular adenomas, 38$67 \%$ of follicular carcinomas, $31-78 \%$ of papillary carcinomas, $0 \%$ of anaplastic carcinomas, and $0 \%$ of medullary carcinomas tested. ${ }^{1,24,38}$ Sequeira et $a l^{39}$ reported TTF-2 expression by in situ hybridization in: $15 / 21(71 \%)$ cases of follicular adenomas, 8/18 $(44 \%)$ cases of follicular carcinomas, $11 / 17$ cases $(65 \%)$ of papillary carcinomas, and $0 / 2$ cases $(0 \%)$ of anaplastic carcinomas. Our results are clearly at variance with previous reports on the subject. The reason for this disagreement is not clear. It may be attributed to a difference in antibodies given that the Pax8 antibody used in the current series was not utilized in previous studies. The reliability of our marker is evident, because we tested it not only on the thyroid neoplasms but also on a variety of normal tissues and common malignant neoplasms. In contrast to the results of Pax8 and TTF-2 staining, our finding of TTF-1 expression in thyroid epithelial neoplasms is in keeping with reported results. ${ }^{15,21,40}$

TTF-2 was not expressed in the non-thyroid normal tissues and tumors tested, whereas Pax8 was expressed in B lymphocytes, the renal tubule, epithelial cells of the fallopian tube and ovarian surface inclusion cyst, and tumors of metanephric and gonadal derivation, such as clear renal cell carcinomas, ovarian carcinomas, and seminomas. The latter findings are in keeping with those reported previously. ${ }^{41,42}$

In summary, although expressed in several tumors, it is evident that Pax8 would serve as a useful marker in the following situations: (1) a solitary or even multiple carcinomas in the lung where primary lung and metastasis from the thyroid gland are considered as an origin (Figure 2a); (2) a metastatic carcinoma in other organs such as bone and brain where lung and thyroid gland are primary sites under consideration; (3) an undifferentiated neoplasm (Figure 2b) of the neck, which involves thyroid gland as well as adjacent organs, such as larynx, trachea, and bronchus; (4) a carcinoma in the thyroid gland or more commonly in the neck where the differential diagnoses include primary thyroid carcinoma and metastatic carcinoma from the lung. This distinction is important since the chemotherapeutic regimens are different, that is, adriamycin for anaplastic carcinoma, and platinum-based chemotherapy for lung carcinoma. ${ }^{43,44}$ The diagnostic dilemma is exemplified by cases where there is uncertainty as to whether the undifferentiated tumor is thyroid based or not. We have seen a case of lung carcinoma mistaken for an anaplastic thyroid carcinoma, because the pathologist was led to believe that the tumor was in the thyroid, while it was simply a lymph node metastasis from a large cell carcinoma of pulmonary origin. Pax8 would have helped significantly in such a context.

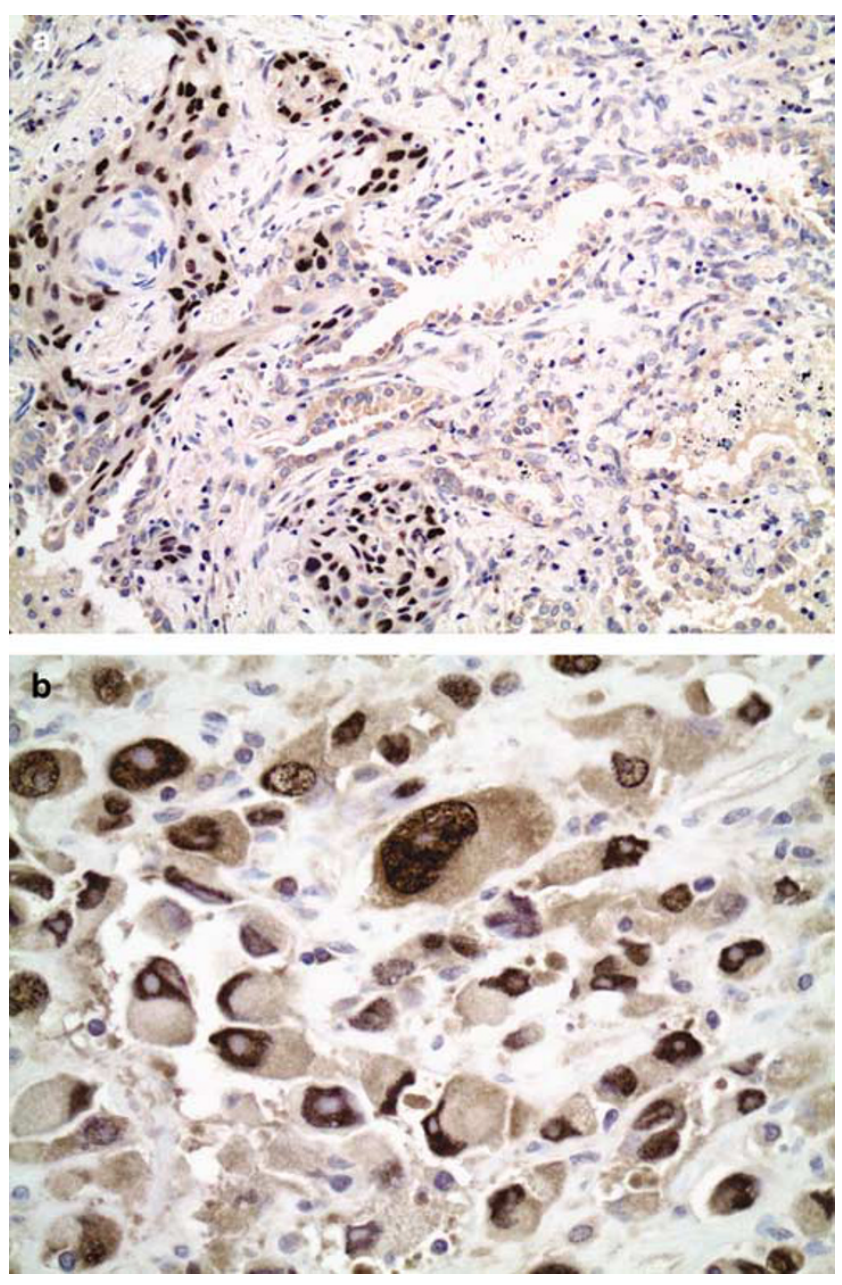

Figure 2 (a) Pax8-positive metastatic anaplastic thyroid carcinoma involving the lung parenchyma. Note that lung tissue is negative for Pax8. (b) Anaplastic/pleomorphic giant cells demonstrating strong nuclear Pax8 expression.

For differentiated thyroid tumors, TTF-2 is as specific a marker as thyroglobulin, and is more specific than Pax8 and TTF-1, but it has no greater utility in anaplastic carcinomas than thyroglobulin does.

\section{References}

1 Zhang P, Zuo H, Nakamura Y, et al. Immunohistochemical analysis of thyroid-specific transcription factors in thyroid tumors. Pathol Int 2006;56:240-245.

2 DeLellis R, Williams E. Tumours of the thyroid and parathyroid. In: DeLellis R, Lloyd R, Heitz P, Eng C (eds). Pathology \& Genetics, Tumours of Endocrine Organs, 1st edn. IARC Press: Lyon, 2004, pp 49-133.

3 Rosai J. Thyroid gland. In: Rosai J (ed). Rosai and Ackerman's Surgical Pathology, 9th edn. Mosby: London, UK, 2004, pp 515-594.

4 Kononen J, Bubendorf L, Kallioniemi A, et al. Tissue microarrays for high-throughput molecular profiling of tumor specimens. Nat Med 1998;4:844-847. 
5 Hoos A, Urist MJ, Stojadinovic A, et al. Validation of tissue microarrays for immunohistochemical profiling of cancer specimens using the example of human fibroblastic tumors. Am J Pathol 2001;158:1245-1251.

6 Jemal A, Siegel R, Ward E, et al. Cancer statistics, 2006. CA Cancer J Clin 2006;56:106-130.

7 Mazzaferri E. Thyroid carcinoma: papillary and follicular. In: Mazzaferri E, Samaan N (eds). Endocrine Tumors. Blackwell Scientific Publications Inc.: Cambridge, MA, 1993, pp 278-333.

8 Colby T, Koss M, Travis W. Carcinoma of the lung; clinical, radiographic aspects, spread, staging, management, and prognosis. In: Colby T, Koss M, Travis W (eds). Tumors of the Lower Respiratory Tract, 3rd series edn. Armed forces institute of pathology: Washington, DC, 1995, pp 107-134.

9 Lin JD, Weng HF, Ho YS. Clinical and pathological characteristics of secondary thyroid cancer. Thyroid 1998;8:149-153.

10 Shimaoka K, Sokal JE, Pickren JW. Metastatic neoplasms in the thyroid gland. Pathological and clinical findings. Cancer 1962;15:557-565.

11 Nakhjavani MK, Gharib H, Goellner JR, et al. Metastasis to the thyroid gland. A report of 43 cases. Cancer 1997;79:574-578.

12 Massin JP, Savoie JC, Garnier H, et al. Pulmonary metastases in differentiated thyroid carcinoma. Study of 58 cases with implications for the primary tumor treatment. Cancer 1984;53:982-992.

13 Shimosato Y, Melamed M, Nettesheim P. In: Shimosato Y, Melamed M, Nettesheim P (eds). Morphogenesis of Peripheral Type Adenocarcinoma of the Lung, vol. I. CRC Press Inc.: Boca Raton, FL, 1982, pp 65-90.

14 Zamecnik J, Kodet R. Value of thyroid transcription factor-1 and surfactant apoprotein A in the differential diagnosis of pulmonary carcinomas: a study of 109 cases. Virchows Arch 2002;440:353-361.

15 Katoh R, Kawaoi A, Miyagi E, et al. Thyroid transcription factor-1 in normal, hyperplastic, and neoplastic follicular thyroid cells examined by immunohistochemistry and nonradioactive in situ hybridization. Mod Pathol 2000;13:570-576.

16 Yatabe Y, Mitsudomi T, Takahashi T. TTF-1 expression in pulmonary adenocarcinomas. Am J Surg Pathol 2002;26:767-773.

17 Bejarano PA, Nikiforov YE, Swenson ES, et al. Thyroid transcription factor-1, thyroglobulin, cytokeratin 7 , and cytokeratin 20 in thyroid neoplasms. Appl Immunohistochem Mol Morphol 2000;8:189-194.

18 Carcangiu ML, Steeper T, Zampi G, et al. Anaplastic thyroid carcinoma. A study of 70 cases. Am J Clin Pathol 1985;83:135-158.

19 LiVolsi VA, Brooks JJ, Arendash-Durand B. Anaplastic thyroid tumors. Immunohistology. Am J Clin Pathol 1987;87:434-442.

20 Rossi G, Cavazza A, Sturm N, et al. Pulmonary carcinomas with pleomorphic, sarcomatoid, or sarcomatous elements: a clinicopathologic and immunohistochemical study of 75 cases. Am J Surg Pathol 2003;27:311-324.

21 Miettinen M, Franssila KO. Variable expression of keratins and nearly uniform lack of thyroid transcription factor 1 in thyroid anaplastic carcinoma. Hum Pathol 2000;31:1139-1145.

22 Ponzoni M, Arrigoni G, Doglioni C. New transcription factors in diagnostic hematopathology. Adv Anat Pathol 2007;14:25-35.
23 Trueba SS, Auge J, Mattei G, et al. PAX8, TITF1, and FOXE1 gene expression patterns during human development: new insights into human thyroid development and thyroid dysgenesis-associated malformations. J Clin Endocrinol Metab 2005;90:455-462.

24 Scouten WT, Patel A, Terrell R, et al. Cytoplasmic localization of the paired box gene, Pax-8, is found in pediatric thyroid cancer and may be associated with a greater risk of recurrence. Thyroid 2004;14: 1037-1046.

25 Pasca dM, Di Lauro R, Zannini M. Pax8 has a key role in thyroid cell differentiation. Proc Natl Acad Sci USA 2000;97:13144-13149.

26 Guazzi S, Price M, De Felice M, et al. Thyroid nuclear factor 1 (TTF-1) contains a homeodomain and displays a novel DNA binding specificity. EMBO J 1990;9: 3631-3639.

27 Park SM, Chatterjee VK. Genetics of congenital hypothyroidism. J Med Genet 2005;42:379-389.

28 Sequeira M, Al Khafaji F, Park S, et al. Production and application of polyclonal antibody to human thyroid transcription factor 2 reveals thyroid transcription factor 2 protein expression in adult thyroid and hair follicles and prepubertal testis. Thyroid 2003;13: 927-932.

29 Clifton-Bligh RJ, Wentworth JM, Heinz P, et al. Mutation of the gene encoding human TTF-2 associated with thyroid agenesis, cleft palate and choanal atresia. Nat Genet 1998;19:399-401.

30 Castanet M, Park SM, Smith A, et al. A novel loss-offunction mutation in TTF-2 is associated with congenital hypothyroidism, thyroid agenesis and cleft palate. Hum Mol Genet 2002;11:2051-2059.

31 Poleev A, Fickenscher H, Mundlos S, et al. PAX8, a human paired box gene: isolation and expression in developing thyroid, kidney and Wilms' tumors. Development 1992;116:611-623.

32 Mittag J, Winterhager E, Bauer K, et al. Congenital hypothyroid female pax8-deficient mice are infertile despite thyroid hormone replacement therapy. Endocrinology 2007;148:719-725.

33 De Felice M, Di Lauro R. Thyroid development and its disorders: genetics and molecular mechanisms. Endocr Rev 2004;25:722-746.

34 Brabant G, Maenhaut C, Kohrle J, et al. Human thyrotropin receptor gene: expression in thyroid tumors and correlation to markers of thyroid differentiation and dedifferentiation. Mol Cell Endocrinol 1991;82:R7-R12.

35 Lazar V, Bidart JM, Caillou B, et al. Expression of the $\mathrm{Na}+/ \mathrm{I}-$ symporter gene in human thyroid tumors: a comparison study with other thyroid-specific genes. J Clin Endocrinol Metab 1999;84:3228-3234.

36 Kusakabe T, Hoshi N, Kimura S. Origin of the ultimobranchial body cyst: T/ebp/Nkx2.1 expression is required for development and fusion of the ultimobranchial body to the thyroid. Dev Dyn 2006; 235:1300-1309.

37 Suzuki M, Katagiri N, Ueda M, et al. Functional analysis of Nkx2.1 and Pax9 for calcitonin gene transcription. Gen Comp Endocrinol 2007;152: 259-266.

38 Puglisi F, Cesselli D, Damante G, et al. Expression of Pax-8, p53 and bcl-2 in human benign and malignant thyroid diseases. Anticancer Res 2000;20:311-316.

39 Sequeira MJ, Morgan JM, Fuhrer D, et al. Thyroid transcription factor-2 gene expression in 
benign and malignant thyroid lesions. Thyroid 2001;11:995-1001.

40 Katoh R, Miyagi E, Nakamura N, et al. Expression of thyroid transcription factor-1 (TTF-1) in human $C$ cells and medullary thyroid carcinomas. Hum Pathol 2000;31:386-393.

41 Narlis M, Grote D, Gaitan Y, et al. Pax2 and pax8 regulate branching morphogenesis and nephron differentiation in the developing kidney. J Am Soc Nephrol 2007;18:1121-1129.
42 Bowen NJ, Logani S, Dickerson EB, et al. Emerging roles for PAX8 in ovarian cancer and endosalpingeal development. Gynecol Oncol 2007; 104:331-337.

43 Are C, Shaha AR. Anaplastic thyroid carcinoma: biology, pathogenesis, prognostic factors, and treatment approaches. Ann Surg Oncol 2006;13:453-464.

44 Scagliotti G. Optimizing chemotherapy for patients with advanced non-small cell lung cancer. J Thorac Oncol 2007;2:S86-S91. 